\title{
DESAFIOS DA GESTÃO ESCOLAR EM MEIO AS DISCUSSÕES DE IDENTIDADE, DIFERENÇA E DIVERSIDADE CULTURAL NO ÂMBITO EDUCATIVO
}

\author{
CHALLENGES OF SCHOOL MANAGEMENT IN THE MIDDLE OF DISCUSSIONS \\ OF IDENTITY, DIFFERENCE AND CULTURAL DIVERSITY IN EDUCATION
}

Maria Thaís de Oliveira Batista*

taholiveira.thais@gmail.com

* Universidade Federal de Campina Grande, Cajazeiras/PB - Brasil.

\section{Resumo}

Este artigo tem o objetivo de analisar a função da gestão escolar frente à diversidade cultural na escola, no tocante aos desafios cotidianos à questão, bem como compreender as potencialidades do projeto político pedagógico nesse processo, em meio ao enfrentamento das questões que envolvem a diversidade existente no cotidiano escolar como um todo. Trazemos as contribuições dos estudos culturais para compreensão das especificidades que perpassam a diversidade da sociedade atual - como as discussões que envolvem as questões de identidade e diferença -, de modo que encontramos em grandes autores, argumentos pertinentes à proposta deste texto e que compõem o interior das instituições de ensino, como também os principais desafios que enfrenta a gestão escolar. A diversidade cultural necessita ser trabalhada no contexto escolar mediante uma postura crítica e reflexiva das instâncias administrativas e pedagógicas, na medida em que se faz necessário oportunizar espaço para que as diferenças possam ser questionadas e compreendidas, proporcionando uma reflexão sobre a multiplicidade de identidades e, sobretudo valores e representações que nos constituem enquanto sujeitos com diferenças diversas. $O$ principal papel da gestão escolar nesse processo em meio aos desafios no tocante à diversidade a ser delineada no Projeto Político Pedagógico, consolida-se em oportunizar de forma democrática, espaço para o diálogo dos diferentes sujeitos e formação continuada dos seus profissionais.

Palavras-chave: Diversidade Cultural. Identidade. Diferença. Gestão Escolar.

\begin{abstract}
This article aims to analyze the role of school management in relation to cultural diversity in the school, regarding the daily challenges to the issue, as well as to understand the potential of the pedagogical political project in this process, in the face of the issues that involve the existing diversity In everyday school life as a whole. We bring the contributions of cultural studies to understand the specificities that permeate the diversity of present-day society - such as discussions involving issues of identity and difference - so that we find in great authors, arguments pertinent to the proposal of this text and that compose the interior Of educational institutions, as well as the main challenges facing school management. Cultural diversity needs to be worked out in the school context through a critical and reflexive posture of administrative and pedagogical instances, since it is necessary to provide space for differences to be questioned and understood, providing a reflection on the multiplicity of identities and, Especially values and representations that constitute us as subjects with different differences. The main role of school management in this process, in the midst of the diversity challenges to be outlined in the Political Pedagogical Project, consolidates itself in a democratic way, providing space for the dialogue of the different subjects and the continuous training of its professionals.
\end{abstract}

Keywords: Cultural Diversity. Identity. Difference. School management. 


\section{INTRODUÇÃO}

Este artigo tem o objetivo de analisar a função da gestão escolar frente à diversidade cultural na escola, no tocante aos desafios cotidianos à questão, bem como compreender as potencialidades do projeto político pedagógico nesse processo, em meio ao enfrentamento das questões que envolvem a diversidade existente no cotidiano escolar como um todo. Trazemos as contribuições dos estudos culturais para compreensão das especificidades que perpassam a diversidade da sociedade atual - como as discussões que envolvem as questões de identidade e diferença -, de modo que encontramos em Giroux (2013), Munanga (1996), Hall (2006) e Woodward (2000) argumentos pertinentes à proposta deste texto e que compõem o interior das instituições de ensino, como também os principais desafios que enfrenta a gestão escolar.

A diversidade é uma temática que permeia uma série de discussões na sociedade contemporânea, na medida em que se estabelece nos mais diversos espaços de debate da área, ao ponto que segundo Gomes (2008, p. 17), ao ser analisada sob uma perspectiva cultural, a diversidade pode ser apresentada a partir de uma "construção histórica, cultural e social das diferenças". É pertinente destacar que essas diferenças são construídas pelos indivíduos de forma relacional em contato com a sociedade no decorrer dos processos culturais e históricos, que se concretizam como um ato adaptativo entre as pessoas e o meio social.

A diversidade cultural necessita ser trabalhada no contexto escolar mediante uma postura crítica e reflexiva das instâncias administrativas e pedagógicas, na medida em que se faz necessário oportunizar espaço para que as diferenças possam ser questionadas e compreendidas, proporcionando uma reflexão sobre a multiplicidade de identidades e, sobretudo valores e representações que nos constituem enquanto sujeitos com diferenças diversas. Tal postura surge atrelada a necessidade de um trabalho coletivo e descentralizador dentro do contexto escolar, ao ponto que requer a compreensão da relevância da gestão escolar nesse processo.

Quando pensamos em diversidade cultural no âmbito escolar, precisamos revisitar a função e principais características do Projeto Político Pedagógico das instituições, que se apresenta enquanto instrumento que contribui para que a gestão escolar tome suas decisões em prol das principais questões que envolvem o contexto da instituição, e que desse modo deve está atento para as questões que emergem da diversidade cultural presente nesse espaço. Sabendo disso, é necessário que professor, corpo gestor e demais profissionais envolvidos, encontrem na elaboração e reelaboração deste documento, as medidas necessárias para suprir as principais limitações e 
carências existentes no espaço escolar - como, por exemplo, as questões que envolvem a diversidade cultural, diferença e identidade nesse contexto.

Desse modo, faz parte da função social da escola, e, por conseguinte da gestão escolar, criar condições para a promoção de uma educação igualitária e condizente com as especificidades do alunado, partindo do princípio do envolvimento e partilha constante de conhecimentos e vivências entre professor-aluno, aluno-aluno e demais membros da comunidade escolar. As ações decorrentes de uma postura crítica e reflexiva acerca da diversidade existente na escola possibilitará, assim, que sejam desmistificadas situações de racismo, preconceito e/ou discriminação racial, pelo qual abrirão espaço para os diversos grupos sociais existentes - e que estão imersos na dinâmica escolar, fazendo com que estes possam assumir as suas identidades.

\section{A DIVERSIDADE CULTURAL SOB UM OLHAR DOS ESTUDOS CULTURAIS}

O debate em torno da diversidade cultural encontra-se consolidado de forma crítica e abrangente nas produções referentes aos estudos culturais, pelo qual percebemos relevante discussão no capítulo Praticando Estudos Culturais nas Faculdades de Educação, elaborado por Henry Giroux (2013), no livro Alienígenas na sala de aula: uma introdução aos estudos culturais em educação de organização de Tomaz Tadeu Silva. Neste capítulo podemos ter uma noção geral sobre os estudos culturais e seu modo de ser concebido dentro das Faculdades de Educação, pela qual Giroux (2013) lança algumas críticas em relação ao currículo, ser concebido, muitas vezes, como ferramenta de reprodução das desigualdades sociais, bem como repressão das diferentes culturas.

O autor questiona acerca da limitação nas Faculdades de Educação, de discussões que abarquem a riqueza de reflexões que os Estudos Culturais disponibilizam para a sociedade como um todo, de modo que critica o fato de muitos modelos tecnocráticos terem, ainda, a possibilidade de agirem sobre os programas educacionais, gerando a disseminação de uma cultura que exclui, na medida em que não atribui relevância as diversas histórias dos grupos culturais abastados da sociedade. Desse modo,

[...] a tradição dominante favorece a contenção e a assimilação das diferenças culturais, em vez de tratar os/as estudantes como portadores/as de memórias sociais diversificadas, com o direito de falar e de representar a si próprios/as na busca de aprendizagem e de autodeterminação (GIROUX, 2013, p.83). 
Nessa realidade, a educação ao priorizar os processos de administração e gerência, tende a reprimir a possibilidade de uma abertura maior de reflexões acerca da democratização da escola enquanto espaço público, ao ponto que isso implica na composição de um corpo docente totalmente controlado e padronizado. Ao negar a diversidade de culturas mediante essas imposições, a escola passa a nadar contra o que é proposto pelos Estudos Culturais, de modo que compreende, muitas vezes, o processo histórico-cultural dos povos como homogêneo e estanque, e não de forma globalizada e dinamizada.

Ao desconsiderar a diversidade cultural dos sujeitos presentes no dia-a-dia das escolas, bem como dos grupos culturais que estão inseridos, os agentes envolvidos no cotidiano das instituições de ensino e o próprio currículo perdem seu caráter político, de modo que não dão abertura para a disseminação de um maior compartilhamento de vivências que caracterizam na construção de uma escola democrática, bem como coparticipante com a formação de identidades. Segundo o autor,

\footnotetext{
Para os Estudos Culturais, a educação gera um espaço narrativo privilegiado para alguns/algumas estudantes e, ao mesmo tempo, produz um espaço que reforça a desigualdade e a subordinação para outros/as. Corporificando formas dominantes de capital cultural, a escolarização frequentemente funciona para afirmar as histórias eurocêntricas e patriarcais, as identidades sociais e as experiências culturais dos/as estudantes de classe média, ao mesmo tempo que marginaliza ou apaga as vozes, as experiências e as memórias culturais dos/as assim chamados/as estudantes da "minoria" (GIROUX, 2013, p.84).
}

Essa forma de dominação de uma sociedade eurocêntrica e patriarcal em meio ao capital cultural e que se tem predominado desde muito tempo, tende a desconstruir a ideia de muitos estudantes mediante a relevância social que a escola, bem como as demais instituições de ensino como as Faculdades de Educação - deveriam nos fazer compreender -, podem acarretar para as suas vidas, de modo que passam a enxergar seu processo de escolarização e formação como ambientes que irão marginalizá-los e oprimi-los mediante a imposição de relações de poder sobre a cultura e o conhecimento a serem compartilhados e construídos nesses espaços.

Os Estudos Culturais aparecem como forma de possibilitar a quem o adota e procura inserilo nas discussões das Faculdades de Educação, bem com instituições escolares, um afastamento mediante a imposição dessa cultura eurocêntrica e homogênea, como forma de promover uma vivência que perpasse o conhecimento disciplinar, chegando ao conhecimento multidisciplinar do vivido, pois, a forma como os conteúdos estão contemplados em disciplinas e que não estabelecem diálogo e relação com as demais, tende a não dar conta dos diversos fenômenos sociais e culturais que emergem cada vez mais na nossa sociedade pós-moderna. 
Para Giroux (2013), essa forma como o currículo está estruturado não condiz com o que é proposto pelos Estudos Culturais, pois, o que vemos sendo reproduzido cada vez mais, é a implementação de currículos imersos em relações de poder e de hegemonia política e cultural de uma determinada classe dominante. Ao ponto que os Estudos Culturais promovem discussões sobre as diversas questões que surgem a todo o momento na sociedade, desde questões de identidade, étnicas, de raça e de poder, na medida em que oferece caminhos para que professores reflitam acerca do reflexo e significado futuro das suas práticas educativas.

É papel dos educadores enquanto formadores de opiniões, considerarem os aspectos multiculturais e raciais existentes na nossa sociedade, de modo que saiam da sua condição de meros transmissores de informações estanques, para um lugar de mediadores do conhecimento necessário às lutas sociais emergentes, tendo em vista a promoção de espaços que promovam a democracia, a partir de uma maior disseminação de conhecimentos que destaquem as produções históricas dos diferentes culturais.

Em relação a essa discussão, Johnson (2006), ressalta que os Estudos Culturais que hoje temos conhecimento, surgiu no final da década de 1950 a partir da história social e da crítica literária, decorrente das influências da teoria marxista. Os Estudos Culturais têm vivenciado momentos em que se deparam com muitas conquistas, resultados de tantas lutas na busca de uma maior disseminação sobre o assunto, de modo que dentre conquistas e descobertas, uma das mais importantes foi a compreensão de que subjetividade e consciência, necessitam serem vistas de acordo com suas formas históricas, bem como o contexto em que se encontram. Para o autor,

Precisamos de histórias dos Estudos Culturais que analisem os dilemas recorrentes e dêem perspectiva a nossos projetos atuais. [...] Para mim, boa parte das fortes continuidades da tradição dos Estudos Culturais está contida no termo singular "cultura", que continua útil não como uma categoria rigorosa, mas como uma espécie de síntese de uma história (JOHNSON, 2006, p.20).

Nessa perspectiva, é preciso que compreendamos o fato e a necessidade dos Estudos Culturais serem vistos de acordo com o que foi e é vivido nos dias atuais, ao ponto que isso não será possível através de uma discussão isolada em disciplinas acadêmicas que não estabelecem relações umas com as outras, mas sim a partir de práticas interdisciplinares que promovam reflexões mais complexas e interrelacionadas das diferentes áreas em torno dos Estudos Culturais, de modo a considerar a complexidade que o envolve.

Segundo Giroux (2013), a linguagem deve ser compreendida pelos estudantes como instrumento que as classes dominantes se utilizam para se manterem sempre sob uma égide social 
que não leva em conta a diversidade cultural existente, de modo que nos remete a uma forma de exclusão e dominação sobre os grupos sociais marginalizados da sociedade. Na medida em que os discursos nas diferentes instâncias não abarcam, em sua maioria, as particularidades das diversas culturas, ao ponto que apresentam-se de forma estanques e fora de contexto, não levando em consideração a realidade sócio-histórica vivida.

Desse modo, é dever das Faculdades de Educação e dos Institutos e Cursos de Pedagogia, promoverem a disseminação de uma nova concepção de democracia. Uma democracia que leve em conta as necessidades específicas de diferentes grupos culturais e que fazem parte dos resultados dessa nova dinâmica social que temos presenciado a algum tempo, na medida em que considerem o processo de construção identitária, a partir do uso da linguagem como instrumento de compartilhamento de experiências e conhecimentos e não como forma de dominação de uma determinada classe.

\section{COMPREENDENDO DIFERENÇA E IDENTIDADE CULTURAL}

Stuart Hall (2006) discorre sobre a possibilidade de estarmos vivenciando uma crise de identidade e que esta, por sua vez, é reflexo de uma série de caminhos trilhados até os dias atuais. O autor nos traz uma série de questionamentos em torno dessa discussão que tornou-se emergente desde o período da modernidade, ou "modernidade tardia" como citada por ele. O autor nos situa a respeito de algumas concepções de identidade desde a era do iluminismo e que perpassam a existência humana, e que estas são materializadas diariamente no cotidiano das instituições de ensino e, por isso, devem ser objeto de análise por parte da gestão escolar. Nessa perspectiva de discorrer acerca das diferentes concepções de identidade dos sujeitos, destaca três delas, que são: o sujeito do Iluminismo; o sujeito sociológico e o sujeito pós-moderno (HALL, 2006).

O sujeito do Iluminismo, diz respeito a uma compreensão de indivíduo completamente unificado e centrado, ao ponto que detinha de uma significativa capacidade de razão mediante os diferentes posicionamentos necessários as diversas questões que emergiam na época; o sujeito sociológico é o indivíduo do mundo moderno, o qual necessita para a sua plena existência social, dos vínculos e das relações que são firmadas com os outros, ao ponto que não se percebe enquanto autônomo e independente dos demais, de modo a construir sua identidade na interação do seu mundo interno com o externo, do seu eu interior com a sociedade. E o sujeito pós-moderno é aquele que não detém de uma identidade formada e fixa, de modo que esta está suscetível às 
transformações advindas da sociedade pós-moderna. E é esse o sujeito que deve ser visto pelo corpo docente e gestor no cotidiano escolar, na medida em que se faz necessário um maior entendimento acerca da diversidade existente no que compete os sujeitos envolvidos nesse processo. Desse modo, surge o debate em torno da crise de identidade, pela qual segundo o autor, essa

[...] identidade plenamente unificada, completa, segura e coerente é uma fantasia. Ao invés disso, à medida em que os sistemas de significação e representação cultural se multiplicam, somos confrontados por uma multiplicidade desconcertante e cambiante de identidades possíveis, com cada uma das quais poderíamos nos identificar - ao menos temporariamente (HALL, 2006, p.13).

Nessa perspectiva, Hall (2006) nos possibilita refletir a respeito de que não existe uma identidade pronta e acabada, concreta e unificada, mas sim uma identidade que está sujeita e suscetível às transformações decorrentes do período e da sociedade em que vivemos, de modo que ao diferenciar esses três tipos de concepções de identidade de sujeitos em três períodos distintos, o autor discorre sobre as transformações decorrentes da modernidade tardia, a qual se encontra diretamente ligada ao sujeito e a concepção de identidade que este adota para si. Transformações essas que necessitam ser conhecidas, analisadas e incorporadas pelo corpo gestor nos momentos de elaboração e reelaboração de aspectos teóricos e práticos condizentes com a diversidade de sujeitos que compõem o âmbito escolar.

Para Hall (2006) - pautado em seus estudos e pesquisas na perspectiva de alguns teóricos da área -, a relação existente entre sociedade moderna e as sociedades da modernidade tardia, fica claro quando nos deparamos com uma análise das descontinuidades provenientes dessa sociedade moderna em virtude dos posicionamentos diversos que os sujeitos tomam ao longo da vida, o que gera grande impacto sobre a identidade cultural destes, dando origem, assim, a essa possível crise de identidade.

O sujeito da sociedade moderna inicial é visto pelo autor como um sujeito individualista e com traços marcados por influências de outros períodos, como o Iluminismo e o período Renascentista, pela qual se compreendia que o homem e nada mais que ele era o centro do universo, porém, com o avançar da sociedade moderna e das transformações dela decorrente, os sujeitos que nela estão inseridos começam também a mudar, no que diz respeito a sua identidade, ao ponto que passa a fazer parte, tornando-se mais integrante do interior das estruturas sociais em que vive. E é nesse momento que surge o sujeito sociológico, a partir do ponto em que se começa a estabelecer relações significativas com o exterior da sociedade, o que irá refletir na construção da identidade desse sujeito moderno. 
O sujeito sociológico segundo o autor, entra em declínio no decorrer das diversas mudanças no âmbito das ciências humanas, que ajudaram a descentralizar esse até então sujeito cartesiano da sociedade moderna. E estas mudanças referem-se a momentos históricos e autores específicos, que auxiliaram nessa mudança de pensamento. Hall (2006) nos aponta cinco marcos que auxiliaram na descentralização desse sujeito na sociedade moderna e na modernidade tardia, são eles: num primeiro momento as contribuições de Marx em torno dos diversos modos de compreender o homem e a posição que ocupa na sociedade a partir do seu trabalho; em um segundo momento, temos Freud e a sua descoberta em torno do inconsciente humano, pelo qual compreende que a identidade não é algo inato ao sujeito, mas sim social e historicamente construído e transformado por este na medida em que vive e interpreta o mundo.

Hall (2006) nos traz as contribuições de Saussure em torno do trabalho com a língua, em que nos diz que “[...] nós não somos, em nenhum sentido, os 'autores' das afirmações que fazemos ou dos significados que expressamos através da língua", pois, "A língua é um sistema social e não individual" (HALL, 2006, p.40), ao ponto que as palavras e os significados que elas exprimem, não são algo fixo, mas sim carregadas de outros múltiplos significados; o quarto tópico que auxiliou no descentramento da identidade do sujeito sociológico, refere-se aos estudos do francês Michel Foucault, que enfatiza e propusera a necessidade de compreendermos um novo tipo de poder, o "poder disciplinar", pelo qual acreditava que os sujeitos deveriam ser vistos mediante sua forma de ser e agir perante o mundo em que vive, ao ponto que cabia aos regimes disciplinares, controlá-los e discipliná-los; e por último temos as contribuições do feminismo e dos movimentos que dele surgiram ao longo dos anos, ao ponto que objetivavam enfatizar diferentes grupos da sociedade e suas respectivas identidades sociais, de modo que acarretaram em uma gama de discussões do papel da mulher dentro da sociedade, bem como questionando as esferas do público e do privado na construção dessas identidades.

Ao caracterizar os momentos de ascensão e declínio do sujeito do iluminismo e do sujeito sociológico para o sujeito pós-moderno, Hall (2006) nos faz refletir acerca dos processos de transformações que perpassam a formação do educando ao longo dos tempos, na medida em que estas transformações fazem parte da formação deste enquanto sujeito coparticipe do desenvolvimento do mundo em que vive, ao ponto que requer da escola um olhar crítico e reflexivo perante essas mudanças, na medida em que para isso faz-se necessário um intenso processo de ressignificação das práticas e princípios que regem as instituições de ensino como um todo.

Ao analisar cada um desses tópicos que deram origem a descentralização da identidade do sujeito sociológico, Hall (2006) nos faz refletir acerca da identidade cultural nacional e das 
transformações decorrentes do que conhecemos por globalização. Para o autor "[...] as identidades nacionais não são coisas com as quais nós nascemos, mas são formadas e transformadas no interior da representação" (HALL, 2006, p.48), e essa concepção de cultura nacional, para o autor, fez com que se padronizassem os diversos âmbitos da sociedade, de modo que se generalizou e homogeneizou as diversas culturas existentes.

O discurso da cultura nacional não é, assim, tão moderno como aparenta ser. Ele constrói identidades que são colocadas, de modo ambíguo, entre o passado e o futuro. Ele se equilibra entre a tentação por retornar a glórias passadas e o impulso por avançar ainda mais em direção à modernidade (HALL, 2006, p.56).

Nessa perspectiva, o autor nos faz refletir acerca da identidade cultural nacional e o modo como ela se dá mediante as diferenças culturais existentes na nossa sociedade. Diferenças quanto à classe, gênero, etnia ou raça, seriam desse modo anuladas mediante essa concepção de identidade nacional? Esse é um questionamento que devemos pensar, o que nos faz refletir acerca da realidade aqui em questão - da homogeneização das identidades -, ao ponto que "em vez de pensar as culturas nacionais como unificadas, deveríamos pensá-las como constituindo um dispositivo discursivo que representa a diferença como unidade ou identidade" (HALL, 2006, p. 61-62).

A globalização é vista pelo autor como mola propulsora de diversas mudanças quanto a compreensão e a descentralização dessa até então identidade cultural nacional que se mostra excludente, o que levou a um maior interesse em torno de particularidades locais das diferentes culturas, originando o que o autor chama de nova articulação entre o global e o local. E é nesse momento que surge uma discussão sobre o hibridismo, pelo qual se compreende que as identidades culturais são essencialmente híbridas, ao ponto que se constroem em um intenso processo de transformações e deslocamentos e que, portanto, estão passíveis de mudanças.

Desse modo, essa noção do global pode nos auxiliar na compreensão de uma educação plural e de uma maior diversidade de saberes e práticas dentro do âmbito das escolas bem como da sociedade em geral, em busca da construção de uma identidade que esteja condizente com as especificidades do momento histórico e do período vivido. Hall (2006) nos possibilita um olhar mais atencioso mediante a nossa capacidade de analisar e interpretar os sujeitos da sociedade moderna e pós-moderna, ao ponto que cabe a nós, compreendermos a existência de uma identidade cultural suscetível à transformações e deslocamentos, na medida em que isso nos ajuda a firmar um entendimento mais seguro em torno da atual identidade que perpassa o período pós-moderno em que vivemos. 
Tais discussões acerca dos processos de construção identitária do sujeito pós-moderno, nos dão abertura para refletir acerca do trabalho da gestão escolar em meio a essa realidade, ao ponto que cabe a esta juntamente com os demais profissionais envolvidos no âmbito escolar, refletirem a necessidade de um olhar cauteloso e investigador mediante a diversidade de sujeitos presentes nas escolas, bem como implementarem possibilidades de caminhos a serem seguidos pelos profissionais, e que possam contribuir para um olhar crítico e reflexivo mediante diferentes questões que perpassam o dia-a-dia das instituições de ensino.

Questões como identidade, diferença e diversidade cultural devem ser vistos enquanto ponto relevante nesse processo, e a formação continuada dos profissionais envolvidos, mostra-se cada vez mais necessária, na medida em que a discussão instaura um novo olhar no âmbito da formação continuada e da organização do trabalho pedagógico no interior da escola.

Quando falamos em identidade e diferença, nos reportamos a Woodward (2000) quando esta nos traz uma reflexão acerca de uma história que se sucedeu na Iugoslávia, em que nos remete a um texto de Michael Ignatieff sobre a guerra entre sérvios e croatas. Em um pequeno texto abordado pela autora, temos acesso às indagações feitas por um estrangeiro, a respeito do por que desses povos vizinhos lutarem entre si e de se acharem tão diferentes uns dos outros. Porém, a resposta do sérvio foi contrária a pergunta do estrangeiro, de modo que deixou a entender que não considera que sérvios e croatas são diferentes entre si, mas sim que fazem parte do mesmo Lixo dos Bálcãs, ressaltando que não há diferenças entre eles. Desse modo,

\footnotetext{
Essa história mostra que a identidade é relacional. A identidade sérvia depende, para existir, de algo fora dela: a saber, de outra identidade (Croácia), de uma identidade que ela não é, que difere da identidade sérvia, mas que, entretanto, fornece as condições para que ela exista. A identidade sérvia se distingue por aquilo que ela não é. Ser um sérvio é ser um 'não-croata'. A identidade é, assim, marcada pela diferença (WOODWARD, 2000, p.9).
}

Esta identidade marcada pela diferença, é aqui compreendida como algo imerso numa diversidade de símbolos que se interrelacionam de forma mútua e que contribuem no entendimento dos pólos contrários e que são resultado das relações sociais estabelecidas ao longo de um determinado período, ou seja, é algo cultural e historicamente construído pelos povos, que tende a expressar tanto um caráter social quanto simbólico ao longo desse processo.

A autora aponta a existência de dois tipos de perspectivas que devem ser vistas para uma melhor análise sobre as discussões que permeiam a temática de identidades. A primeira seria a essencialista, que compreende a identidade de forma não heterogênea, mas sim como algo homogêneo e visto como produto em que não há a possibilidade de modificações, na medida em 
que se mostra como algo pronto e acabado, e que, portanto, não está sujeito a qualquer tipo de modificação. A segunda seria a não essencialista, que defende o caráter de heterogeneidade que perpassa o processo de construção das identidades, de modo que diferente da essencialista, deve ser compreendida a partir das diferenças, das modificações que são realizadas ao longo desse processo, pautando-se numa posição de inacabamento e sendo construída simbólica e socialmente. Nessa perspectiva,

[...] Uma definição essencialista da identidade 'sérvia' sugeriria que existe um conjunto cristalino, autêntico, de características que todos os sérvios partilham e que não se altera ao longo do tempo. Uma definição não-essencialista focalizaria as diferenças, assim como características comuns ou partilhadas, tanto entre os próprios sérvios quanto entre os sérvios e outros grupos étnicos. Uma definição não-essencialista prestaria atenção também às formas pelas quais a definição daquilo que significa ser um 'sérvio' têm mudado ao longo dos séculos (WOODWARD, 2000, p.12).

Essa discussão sobre a identidade vista sob uma perspectiva essencialista e não essencialista, nos faz refletir acerca dos processos de planejamento e organização do trabalho pedagógico no interior das instituições de ensino, na medida em que estas, em sua maioria, tendem a reproduzir o discurso da igualdade como forma de reprimir e omitir os preconceitos existentes em seu âmago, porém, sem levar em conta o fato de que ao priorizarem o discurso da igualdade, estão desvalorizando as diferenças dos sujeitos presentes nesse espaço, na medida em que mascaram a diferença com uma falsa igualdade.

Ao longo do levantamento das questões de identidade e diferença, Woodward (2000) ressalta que o entendimento de ambas como algo não estático e sujeito a modificações, requer um olhar para as interpretações que são dadas pelos diferentes povos, de modo que é a partir dessa atitude, que poderemos estar conscientes da diversidade de posicionamentos que se interpenetram na sociedade ao longo do tempo, independentemente de tempo e espaço em que estas estejam inseridas. Pois, a identidade ao se referir as principais diferenças de um grupo para outro, deve ser um reflexo da própria dinâmica desse grupo.

Em relação a identidade e a diferença como possibilitadoras no processo de representação e aquisição de sentidos por parte dos sujeitos, Woodward (2000) discorre que é essa capacidade de representação que permeia a criação dos símbolos, nos quais as experiências dos seres humanos ganham sentido. A cultura aqui ganha lugar de destaque ao longo desse processo de representação, pois, modela a construção dessa identidade, ao ponto que concretiza a existência de inúmeras e diversas possibilidades de concebê-la - cultura essa que deve ser valorizada pelo corpo gestor nos momentos de elaboração e reelaboração dos princípios que regem a instituição. 
Para a autora, a identidade depende da diferença, na medida em que é através da simbologia e da própria exclusão social que esta se concretiza, pois, “[...] as identidades são contestadas. [...] A discussão sobre identidades sugere a emergência de novas posições e de novas identidades, produzidas, por exemplo, em circunstâncias econômicas e sociais cambiantes" (WOODWARD, 2000, p.19). Nessa perspectiva, a construção das identidades requer que possamos analisar e identificar o lugar do qual falamos, pois, este se refere a posicionamentos históricos e culturais específicos de diferentes sujeitos e grupos sociais.

Em meio a essa discussão, a autora ressalta, também, as relações existentes entre identidade e subjetividade, pela qual compreende que

[...] A subjetividade envolve nossos sentimentos e pensamentos pessoais. Entretanto, nós vivemos nossa subjetividade em um contexto social no qual a linguagem e a cultura dão significado à experiência que temos de nós mesmos e no qual nós adotamos uma identidade" (WOODWARD, 2002, p.55).

Sabendo disso, cabe aos sujeitos se posicionarem a si próprios, na medida em que os lugares e posicionamentos que assumimos dentro da sociedade e dos grupos sociais em que estamos inseridos constituem a nossa identidade, e a escola juntamente com o espaço familiar apresenta-se enquanto espaço inicial pelo qual os educandos apoiam e firmam os seus processos de construção identitária. Identidade essa que está em constante processo de mutação, na medida em que diz respeito a própria dinâmica não-fixa da sociedade em que vivemos.

Com isso e tendo plena compreensão de que a identidade é marcada pela diferença, acreditamos que os sistemas classificatórios produzidos pela sociedade são determinantes para esse processo, na medida em que dão significado as diferenças existentes. E que precisam, desse modo, estarem imersos nos discursos e práticas no âmago das instituições de ensino, na medida em que fazem parte do processo de constituição de uma diversidade de sujeitos envolvidos nesse espaço.

\section{O PROJETO POLÍtico PEDAGógico COMO ALIADO DA GESTÃo No TRABALHO COM A DIVERSIDADE NA ESCOLA PÚBLICA}

A escola consolida-se enquanto um dos ambientes em que encontramos expressiva diversidade no que compete a diferentes questões do âmbito social, e por isso deve desenvolver um trabalho pautado numa perspectiva democrática e igualitária, pelo qual todos os educandos possam enxergar-se a partir do respeito as suas peculiaridades, sem haver a ideia de superioridade ou inferioridade entre os grupos de estudantes mediante diferentes questões que se sobrepõem. 
Enquanto instância formadora, a escola faz parte dos processos que perpassam a formação integral do ser humano para o exercício da sua cidadania. Nesse sentido, a instituição de ensino pública se destaca como um ambiente educativo em que as diferenças de grupos e etnias se encontram, e por isso todo o corpo docente que compõe a escola, bem como a gestão, necessitam de um olhar reflexivo e cauteloso diante das ações e problemáticas que venham a surgir no cotidiano escolar (MUNANGA, 1996; GIROUX, 2013; GOMES, 2008).

Seguindo a mesma linha de raciocínio, Vasconcelos (2013) nos traz que a escola pública no Brasil enfrenta uma série de desafios estruturais no tocante a seu funcionamento e razão de ser. Isto também se reverbera com ênfase no plano do reconhecimento e da valorização dos seus profissionais, na grande maioria, bem como no pouco investimento em recursos humanos, físicos e/ou materiais. Estes obstáculos aparecem de modos muito comuns, nas mais diferentes regiões, fala-se de problemas tanto nesses aspectos quanto de descaso e desinteresse com a causa da educação, enquanto obrigação do Estado, que por sua vez, tem o dever de oferecer educação de qualidade para todos. A educação pública que se almeja é aquela que possibilite aos educandos, uma formação que lhe permita identificar problemas, elaborar hipóteses e propor soluções para diferentes vivências que perpassam o seu cotidiano.

A escola pública ganha força com a união de todos os seus membros que devem se unir em torno da elaboração de seu documento primordial, que é o Projeto Político Pedagógico, que surge da perspectiva coletiva, ou seja, de unidade que requer o compromisso de todos em sua elaboração e execução contínua em parceria, porém, ainda é preciso avançar bastante, no que diz respeito ao Projeto Político Pedagógico-PPP, porque ele não ganhou ainda, no geral, o devido empenho da gestão escolar e nem, também, dos demais membros responsáveis por uma participação consolidada para o bom funcionamento da escola pública enquanto patrimônio público qualificador dos processos de socialização e de geração de trabalho, renda e cidadania que deve ir desde a sua elaboração até a execução deste. Documento este em que precisam estar explícitos os princípios teórico-metodológicos que lidarão, por exemplo, com as questões que envolvem identidade e diferença no contexto escolar em meio à diversidade de sujeitos presentes nesse cenário.

Vasconcelos (2013, p. 17) defende que o PPP é o "plano global da instituição. Pode ser entendido como sistematização, nunca definitiva, de um processo de planejamento participativo, que se aperfeiçoa, se objetiva na caminhada, define claramente o tipo de ação educativa a ser realizada". A própria identidade da escola se constitui a partir do trabalho dos diferentes profissionais da instituição em meio aos processos de se pensar e elaborar uma proposta de Projeto Político Pedagógico, ao ponto que se faz essencial atentar-se para o fato de que grande parte da Revista Valore,Volta Redonda, 2 (I): I68-185., Junho/20I7 
qualidade desse trabalho, depende significativamente como nos aponta Vasconcelos (2013), das características de flexibilidade e autonomia presentes na elaboração do PPP.

Os processos de elaboração e reelaboração do PPP devem levar em consideração o traçar de metas para que desconstrua o preconceito e a discriminação racial perante aos diversos modos culturais que se apresentam na sala de aula. O ensino deve ser pautado numa perspectiva de igualdade, proporcionando o respeito ao próximo, fazendo com que os educandos possam desenvolver uma postura ética. O currículo escolar deve ir ao encontro da realidade dos educandos, como também ao contexto social em que a escola se encontra, considerando os aspectos históricos, sociais e culturais, desenvolvendo, assim, uma educação democrática e igualitária (SACRISTÁN, 2000; GOMES, 2008). Desse modo, o

Projeto Pedagógico [...] é um instrumento teórico-metodológico que visa ajudar a enfrentar os desafios do cotidiano da escola, só que de uma forma refletida, consciente, sistematizada, orgânica e, o que é essencial, participativa. É uma metodologia de trabalho que possibilita ressignificar a ação de todos os agentes da instituição (VASCONCELOS, 1995, p. 143)

A construção do PPP deve ocorrer em coletividade, visto que este é um documento que visa o bom andamento do processo educacional como um todo, revendo sempre as dificuldades enfrentadas pela escola, pensando sempre no seu melhoramento, portanto, a participação da comunidade escolar se faz relevante e obrigatória para que esse documento venha a trazer contribuições para um efetivo funcionamento e desempenho da escola.

Desse modo, com a construção coletiva desse documento norteador da vida escolar, os demais projetos, ideias e representações de todos podem direcionar o trabalho educacional a um sentimento de pertença, por parte dos sujeitos envolvidos, mediante a escola e as questões que dela advém, visando a socialização de conhecimentos científicos e diversificados, o fomento de competências e habilidades e a construção de saberes e/ou de outros tipos de conhecimentos, no que diz respeito também, às vivências e realidades sociais trazidas por discentes - e a gestão apresentase enquanto relevante epicentro desse processo de articulação.

É nesse sentido que compreendemos o PPP enquanto aliado da gestão escolar no trabalho com a diversidade na escola, pois, segundo Vasconcelos (1995) a prática do professor deve estar de acordo com o que existe no projeto, na medida em que se subentende que o professor apresenta-se enquanto sujeito relevante nos momentos de contribuições na sua elaboração e não deve fugir daquilo que se propôs a realizar no decurso do ano letivo. 
Sendo assim, diante do grande número de profissionais da educação que não detêm de um relacionamento próximo com os processos de elaboração e implementação do PPP na escola pública, se faz necessário que educadores, de um modo geral, conheçam as peculiaridades que envolvem o Projeto Político Pedagógico, para que no momento da construção deste instrumento indispensável, se percebam como sujeitos dessa construção, e analisem de forma cautelosa as principais peculiaridades que envolvem o cotidiano das instituições, como a diversidade cultural que perpassa esse espaço.

Nesse sentido, segundo Woodward (2000) a escola como uma instituição que está integrada ao contexto social, deve atribuir valores as diferenças que nela se encontram, desmitificando os estereótipos e desenvolvendo uma prática pedagógica que contemple a diversidade cultural dos educandos.

Para Sacristán (2000) e Gomes (2008), cabe a escola criar um modo que possibilite uma reeducação sobre as práticas pedagógicas direcionadas aos diferentes sujeitos. Todavia o que se quer não só apenas a inclusão dessas pessoas nas escolas, mas todo um trabalho que venha a promover o respeito e o reconhecimento da diversidade, favorecendo a socialização dos alunos e de toda a equipe escolar.

Para Munanga (1996), é necessário ressignificar os aspectos que envolvem as diferentes culturas no nosso país, na medida em que essa ressignificação não deve se restringir somente para as pessoas de raça negra, sendo muito pertinente e interessante que os alunos de outras ascendências étnicas também recebam essa orientação, isto é, recebam uma educação pautada na formação a partir de um olhar sobre a sua cultura, a fim de promover a afirmação de sua identidade. Afinal, os brasileiros não são somente descendentes de gregos e romanos, anglo-saxônicos e latinos devido à ancestralidade europeia, mas são também os descendentes de africanos, de povos indígenas, de orientais, árabes e judeus e até mesmo de ciganos.

Nessa realidade, o PPP vai se constituindo como a possibilidade de novas formas de resolução de problemas, ou mesmo uma nova forma de atuação dos profissionais, no alcance de metas e superação de obstáculos existentes no cotidiano das instituições e que tendem a limitar o espaço disponível para uma diversidade de sujeitos nesse contexto. E assim, percebemos a clara necessidade e a importância do PPP como um documento orientador de posturas, das metodologias e teorias realizadas na instituição escolar, pois, partimos do pressuposto de que as pessoas têm intencionalidades ao executar uma ação, e se tornam a identidade das instituições de ensino. 


\section{CONSIDERAÇÕES FINAIS}

A partir do estudo sobre a temática diversidade cultural e das questões referentes a diferença e identidade cultural discutidas no texto, acreditamos que o Projeto Político Pedagógico é sim um grande aliado da gestão escolar nesse processo, na medida em que permite aos diferentes profissionais pensarem em uma prática que não permita, por exemplo, aos alunos afrodescendentes negarem sua identidade afro-brasileira e que promova uma identificação de si com sua história. Essa deveria ser uma das principais preocupações da escola.

A escola necessita apresentar-se enquanto espaço de afirmação de identidades, ou seja, um espaço de desconstrução de atitudes preconceituosas existentes, entretanto, esta responsabilidade não deve ser dada de forma isolada somente aos professores, mas sim ser uma responsabilidade atribuída a todos que compõem a comunidade escolar, principalmente a gestão escolar, pois, todos que ali estão se constituem enquanto agentes fundamentais no processo de construção da democracia brasileira.

Segundo Woodward (2000), a identidade é relacional e marcada por meio de símbolos relativos a outras identidades. Sabendo disso, esta depende da maneira como as relações dialógicas são estabelecidas com os outros, pois, a idéia que um indivíduo faz de si mesmo, de seu "eu", é intermediada pelo reconhecimento obtido dos outros em decorrência de sua ação e esse é um movimento pelo qual passa todo e qualquer processo identitário.

O surgimento dos Estudos Culturais possibilita a compreensão de uma relação recíproca entre poder, conhecimento e cultura a partir dos processos de transformações históricas decorrentes ao longo do tempo, ao ponto que cabe as instituições de ensino, acompanharem tais mudanças e disponibilizarem práticas educativas que contemplem a diversidade existente na sociedade, bem como a necessidade de um trabalho interdisciplinar pautado num processo crítico e reflexivo do vivido, atuando, assim, como cultivadores de um ambiente democrático e aberto a discussões que emergem a todo o momento na sociedade e que, portanto precisam ser discutidos.

No que diz respeito ao contexto social e escolar, percebe-se que são inúmeras as discussões acerca da diversidade envolvendo culturas dos povos brasileiros, mas em se tratando dessa realidade materializada na prática, compreende-se que ainda se encontra como algo muito ausente no meio social, pelo qual o preconceito ao diferente ainda persiste em se sobrepor perante aos diversos modos de atuação de indivíduos, constituindo-se como hábito que ainda se encontra fortemente nos dias atuais. 
Ao se trabalhar as diversas culturas presentes no Brasil em sala de aula, à escola favorece aos educandos uma compreensão do seu próprio valor, e consequentemente promovendo a autoestima. Com isso a escola deve propiciar um ambiente que possam constituir relações de confiança, para que os estudantes possam se considerar sujeitos em formação, nesse sentido professores e funcionários devem desenvolver um trabalho que é denominado ao conhecimento a história de cada educando, considerando os mesmos como sujeitos sociais em determinada sociedade, independentemente da sua cor ou etnia.

É preciso colocar o PPP em prol dessas questões que perpassam o contexto escolar, como forma de propor a partir da elaboração do documento, o encontro com uma educação democrática e de qualidade, na medida em que se torna responsabilidade inicial da gestão escolar, em promover a partir de um trabalho coletivo e descentralizador, processos de elaboração e reelaboração que levem em conta a diversidade existente no espaço escolar - como forma de disseminar, assim, a existência de práticas condizentes com a diversidade de sujeitos presentes no seu âmago.

O principal papel da gestão escolar nesse processo em meio aos desafios no tocante à diversidade a ser delineada no Projeto Político Pedagógico, consolida-se em oportunizar de forma democrática, espaço para o diálogo dos diferentes sujeitos e formação continuada dos profissionais, como forma de virem a se basear numa prática perpassada pela alteridade, pelo qual possam partilhar seus conhecimentos e experiências diversas, com o intuito de auxiliar em um trabalho de qualidade mediante a diversidade encontrada das instituições de ensino.

É preciso que a gestão escolar considere, assim, a educação uma cultura e a escola um lugar de culturas plurais. Que compreenda e valorize a relação de pertença e identidade dos diferentes sujeitos, e a relevância da formação continuada nesse processo, por apresentar-se enquanto instância aprendente formada por uma equipe de educadores em formação face à organização do trabalho pedagógico para além da sala de aula, bem como a necessidade da participação dos diferentes sujeitos nos processos decisórios que a constituem em meio as bases de formação humana à luz dos processos de escolarização.

\section{REFERÊNCIAS}

GIROUX, Henry. Praticando Estudos Culturais nas faculdades de educação. In SILVA, Tomaz Tadeu (org.) Alienígenas na sala de aula: uma introdução aos estudos culturais em educação. $11^{\text {a }}$ Ed. Rio de Janeiro, Vozes, 2013. p.83-100. 
GOMES, Nilma Lino. Indagações sobre currículo: diversidade currículo. Organização do documento: Jeanete Beauchamp, Sandra Denise Pagel, Aricélia Ribeiro do Nascimento. Brasília: Ministério da Educação, Secretaria de Educação Básica, 2008.

HALL, Stuart. A identidade cultural na pós - modernidade / tradução Tomaz Tadeu da Silva, Guacira Lopes Louro - 11. Ed.- Rio de janeiro: DP\&A, 2006.

JOHNSON, Richard. O que é afinal, estudos culturais? In: JONHSON, Richard; ESCOSTEGUY, Ana; SCHULMAN, Norma. O que é afinal, estudos culturais? Belo Horizonte: Autêntica, 2006. p.07-132. Tradução de: Tomaz Tadeu da Silva.

MUNANGA, Kabengele. Mestiçagem e experiências interculturais no Brasil. In: SCHWARCZ, Lilia Moritz; REIS, Leticia de Souza (orgs.). Negras Imagens. São Paulo: Edusp, 1996, p. 179-193.

SACRISTÁN, José Gimeno. O currículo: uma reflexão sobre a prática. Tradução Ernani F. da Fonseca. 3. Ed. Porto Alegre: Artmed, 2000.

VASCONCELOS, Celson dos Santos. Projeto Político-Pedagógico: considerações sobre a sua elaboração e concretização. In: Coordenação do trabalho pedagógico: do projeto políticopedagógico ao cotidiano da sala de aula. São Paulo: Libertad Editora, 2013.

VASCONCELOS, Celson dos Santos. Planejamento: plano de ensino-aprendizagem e projeto educativo. São Paulo: Libertad, 1995.

WOODWARD, Kathryn. Identidade e diferença: uma introdução teórica e conceitual. In: SILVA, Tomaz Tadeu da (org). Identidade e diferença - a perspectiva dos estudos culturais. Petrópolis: Vozes, 2000.

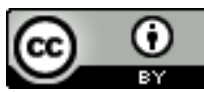

Este obra está licenciada com uma Licença Creative Commons Atribuição 4.0 Internacional. 